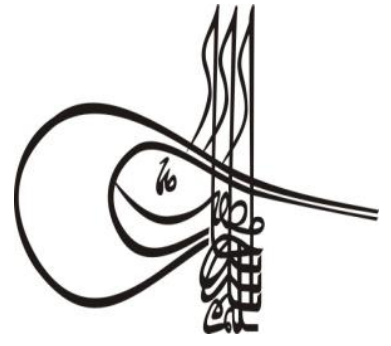

Research Article/Araştırma Makalesi
Article Info/Makale Bilg is i

Received/Geliş: 11.08 .2019

Go Report Dates/Rapor Tarihleri: Referee 1 (12.09.2019)-Referee 2 (14.10.2019)

This article was checked by iThenticate.

\section{Turkists Stutís \\ Social Sciences}

Volume 14 Issue 5, 2019, p. 2579-2596

DOI: 10.29228/TurkishStudies.39391

ISSN: 2667-5617

Skopje/MACEDONIA-Ankara/TURKEY

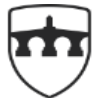

INTERNATIONAL BALKAN UNIVERSITY

EXCELLENCE FOR THE FUTUR IBU.EDU.MK

SAccepted/Kabul: 15.10 .2019

\title{
ÇAĞDAŞ SANATTA KAMUFLAJ STRATEJİLERİ
}

\author{
Metin UÇAR*
}

\begin{abstract}
öz
Kamuflaj; herhangi bir canlının kendini savunma ve saldırı amacıyla yaptığ en aktif eylemlerden birisidir. Bu eylem hayvanlar aleminden alınmış olmasına rağmen sanatçıların katkısıyla modern dönemde ortaya çıkan iki büyük savaşta askeri alanda kullanılmaya başlayan bir stratejiye dönüşmüştür. Modern sonrası dönemde ise askeri alan yanında bireyin sosyal, psikolojik gizlenmesi anlamında çağdaş sanat alanında bir kavram olarak kullanılmaya başlamıştır. Çalışma, kamuflaji bir saklanma ve gizlenme stratejisi olarak ele alan çağdaş sanatçıları, eserlerini ve eserlerindeki kavramsal yaklaşımları konu edinmektedir. Konu ile ilgili olarak yapılan araştırmada, çağdaş sanat uygulamalarında kamuflajı modern ve öncesi dönemdeki kullanımından farklı bir kavram olarak ele alıp inceleyen çok sayıda sanatçı tespit edilmiștir. Çağdaş sanatta bir kavram olarak ortaya çıkan kamuflajı bir strateji olarak ele alan eserleri araştırmak, incelemek ve kavramsal bir temel üzerine oturtmak eserlerin anlaşılması açısından önem taşımaktadır. Araştırma literatür taraması ve doküman incelemesi yöntemi ile yapılmıştır. Bu kapsamda kamuflajın tanımı, çeşitleri, kullanım amaçları ve tarihsel süreçte gelişimi ele alınmış, çağdaş sanatçıların stratejik bir tavırla ortaya koydukları yaklaşımlar ve yaptıkları çalışmaların kavramsal bir çerçeve üzerinden sorgulanması ve yorumlanması amaçlanmıştır. Bu temel amaç doğrultusunda yapılan araștırmada, sanatın kamuflajla 20. Yüzyıl başlarında başlayan ve günümüze kadar farklılaşarak gelen ilişkisi içerisinde çağdaş sanatçıların kamuflajı gizlenme, oyun, bedenleme, cinsiyet, kimlik ve kendisine yabancilaşma gibi kavramlarla ele alarak sanatsal ifade aracına dönüştürdükleri görülmektedir.
\end{abstract}

Anahtar Kelimeler: Çağdaş sanat, Kamuflaj, Strateji, Gizlenme. 


\title{
CAMOUFLAGE STRATEGIES IN CONTEMPORARY ART
}

\begin{abstract}
As a concept, camouflage is one of the most active actions of any living creature for self-defense and attack. Although this action was taken from the animal kingdom, it has become a strategy that has been used in the military field in the two great wars that emerged in the modern era with the contribution of the artists. In the post-modern era, it has started to be used as a concept in the field of contemporary art in terms of social and psychological concealment of the individual. Contemporary art represents the post-modern era, which uses concepts as a tool based on an intellectual process. In this context, the study includes contemporary artists who consider camouflage as a hiding and concealing strategy, their works and conceptual approaches in their works. Numerous artists, who examined as a concept different from using of camouflage in contemporary art, have been identified. It is important to investigate, examine, and place on a conceptual basis emergent new way of expression in the relationship between contemporary art and camouflage. The research has been carried out with literature review and document analysis method, the definition of the camouflage style, types, intended purposes and development of in the historical process have been discussed, the approaches and the works of contemporary artists with a strategic attitude is aimed to be questioned and interpreted through a conceptual framework. In this research conducted in line with this main purpose, in the relationship between art and camouflage, which began at the beginning of the twentieth century and differentiated to the present day, it is seen that contemporary artists have transformed camouflage into concepts of concealment, play, incarnation, gender, identity and alienation.
\end{abstract}

\section{STRUCTURED ABSTRACT}

The word camouflage, which is derived from the French word camoufleur and transferred in Turkish Language as "kamuflaj", is defined as a disguise and abscondence in the Turkish Language Institution dictionary for detection and recognition of the subject. In the simplest definition, Camouflage is considered a strategy that humans borrow to survive from the animal kingdom to conceal and transform themselves. The strategy of hiding or imitating the environment in the animal kingdom has also been a model for the development of concealment strategies in battlefields (Blechman, 2004). While military usage has a limited meaning of hiding soldiers and materials in order to avoid the identification of the enemy, its meaning has expanded in time and it has been used to "hide the true identities of individuals and groups in various ways (Tamahkaroğlu, 2018).

Camouflage is first seen as a survival strategy in Charles Darwin's book which is dated 1859 and named the Origin of Species (Darwin, 1976, 109-110). In the following years, philosophers such as Nietzsche, Kafka and Lawrence have made a matter of debate natural camouflage with examples from the animal kingdom over the philosophy of visibility 
/ invisibility to determine their ideological references. Roy Behrens has been the most scientifically researching relationship between camouflage and art. In his article, which is named "On Visual Arts And Camouflage", he gave examples of both over natural and artistic camouflage. Otherwise, Some of his publications, which are named Art and Camouflage: Concealment and Deception in Nature, Art and War (1981), "The Art of Dazzle Painting (1991), On Max Wertheimer and Pablo Picasso: Gestalt Theory, Cubism and Camouflage (1998), The Role of Artists in Ship Camouflage During World War I "(1999)," Revisiting Gottschaldt: Embedded Figures in Art, Architecture and Design (2000), "Architecture, Art and Camouflage" (2005), "Color and Camouflage" (2010), include research and studies on the relationship between camouflage and art. Chesney, have questioned the camouflage and artist relationship in his book which named CHR the art of camouflage (1941). Cork, R. Bitter Truth: Avant-Garde art and the Great War. New Haven, Connecticut (1994) explores the revival of the war waged by soldiers who are now considered avant-garde artists. In his article "Cubisme et Camouflage" (1993), D. Delouche focused on the relationship and history of cubism with camouflage.

A Elias. Camouflage Australia: Art, Nature, Science and War, (2011) contains information about art, nature, science and military experts about the Second World War. Krass, P. Portrait of War: The US Army's First Combat Artists and the Doughboys' Experience in WWI (2007). Observations and topics of camouflage are told by eight American artists who are participated in World War II.

In the literature, the relationship between the concept of camouflage and art is mostly associated with the military field and modern art. The relationship between contemporary art and camouflage In Behrens' article which is named On Visual Arts And Camouflage, is emphasized that the relationship between contemporary art and camouflage is the area to be investigated (Behrens, 1978: 204). Among the researchers, who deal with the relationship between art and camouflage with contemporary art dimension, is the primary book which is Spanish M. Méndez Baiges's named Camuflaje: Engaño y Ocultación En el Arte Contemporaneo. The author, who has articles on camouflage about modern and following period art, presents the diversity and activities of camouflage-related art in the modern and subsequent periods in this book (Méndez, 2007: 1-334). Méndez and Pizarro's "Camuflajes Exhibition Catalouge" presents a richly illustrated catalog of an international art exhibition that is opened on camouflage in Spain in 2009 (Mendez and Pizarro, 2009: 1-248). The catalog includes different artists' art works and comments. Another exhibition catalog of regarding this issue, which is curated by Ann Elias and Nicholas Tsoutas, is an edition named as "Camouflage Cultures, Surveillance, Communities, Aesthetics and Animal. It includes Australian contemporary artists' artworks and articles about camouflage. B. Richardson, Andy Warhol: Camouflage (1999). This is another exhibition catalog of Warhol's dated 1986, exhibited on camouflage paintings and silk screens. In A. Zohar's article which is named "Strategies of Camouflage: Depersonalization, Schizoanalysis and Contemporary Photography (2014), he interpreted camouflage in the field of visual arts as a strategy in terms of schizoanalytic with movement of the point of view of Deleuze. In Paola Fabbri's 
article, that is named é Sémiotique, Stratégies, Camouflage" (2015), he examined camouflage as a strategy based on semiotical approach. Renaud Bouchet, in her article Dans Mémoires Du Camouflage de la Grande Guerre Dans L'art Contemporain" (2016), includes the memories of world wars in contemporary art. The article published by Natasha Hébert in 2019 "Camouflage Art Contemporain Africain (2019) The relationship between African art and camouflage is dealt with from the aspect of contemporary art.

Applications and researches about the relationship between camouflage and contemporary art are found after the 1980s. This was especially influenced by the change and transformation in social life after 1980 and the fact that camouflage became a permanent problem of global change as a new cultural reality. This problem is reflected in the perceptions of the artists and their works not only as a new reality of daily life but also as a metaphor of the object that conceals the existence of the subject and tries to replace it. Contemporary art refers to the postmodern era, which uses concepts as a tool based on an intellectual process. In this context, the study includes post-1960 contemporary artists who consider camouflage as a hiding and concealment strategy, their works and conceptual approaches in their works. Many artists, who examined as a concept different from the use of camouflage in contemporary art, have been identified. It is important to investigate, examine, and place on a conceptual basis emergent new way of expression in the relationship between contemporary art and camouflage. In this context, the definition, style, types, purposes of usage and development of camouflage technique in literature review method and its development in the historical process are discussed and the approaches and works of contemporary artists are questioned through a conceptual framework. In this research conducted in line with this main purpose, in the relationship between art and camouflage, which began at the beginning of the twentieth century and differentiated to the present day, it is seen that contemporary artists have transformed camouflage into concepts of concealment, play, incarnation, gender, identity and self alienation.

Keywords: Contemporary art, Camouflage, Strategy, Concealment

\section{Giriş}

Fransızca camoufleur kelimesinden türetilmiş ve Türkçeye kamuflaj olarak giren kelime Türk Dil Kurumu sözlügünde öznenin tespiti ve tanınmamasına yönelik bir saklanma, gizlenme olarak tanımlanmaktadır. Kamuflaj, en basit tanımıyla insanların hayatta kalabilmek için kendilerini gizlemek ve dönüştürmek için hayvanlar aleminden ödünç aldığı bir strateji olarak kabul edilir. Hayvanlar aleminde gizlenmek ya da çevreyi taklit etme stratejisi savaş alanlarındaki gizlenme stratejilerinin geliştirilmesine de model olmuştur (Blechman, 2004). Askeri kullanımı düşmanın tespitinden kaçınmak amaciyla askerlerin ve malzemelerin gizlenmesini ifade eden sınırlı bir anlama sahipken zaman içerisinde anlamı genişlemiş, kişi ve grupların çeşitli yollarla gerçek kimliklerini saklamaları için de kullanılmaya başlanmıştır.

Kamuflaj, hayatta kalma stratejisi olarak ilk kez Charles Darwin'in 1859 tarihli Türlerin Kökeni Üzerine adlı kitabında görülür (Darwin, 1976, 109-110). Sonraki yıllarda Nietzsche, Kafka ve Lawrence gibi düşünürler ideolojik referanslarını belirlemek için doğal kamuflajı hayvanlar aleminden örneklerle 
görünürlük/görünmezlik felsefesi üzerinden tartışma konusu yapmışlardır (Zohar, 2014: 8). Kamuflaj ile sanat arasındaki ilişkiyi bilimsel açıdan en fazla araştıran Roy Behrens olmuştur. "On Visual Arts And Camouflage" adlı makalesinde hem doğal hem de sanatsal kamuflajlar üzerinden örnekler vermiştir. Bunun dışında Art and Camouflage: Concealment and Deception in Nature, Art and War, (1981) "The Art of Dazzle Painting (1991), On Max Wertheimer and Pablo Picasso: Gestalt Theory, Cubism and Camouflage (1998), The Role of Artists in Ship Camouflage During World War I" (1999), "Revisiting Gottschaldt: Embedded Figures in Art, Architecture and Design (2000), "Architecture, Art and Camouflage" (2005), "Color and Camouflage" (2010) adlı bazı yayınlarında kamuflaj sanat ilişkisi üzerine yaptığı araştırma ve incelemeleri bulunmaktadır. Chesney, C.H.R. The Art of Camouflage (1941) adlı kitabında kamuflaj sanatçı ilişkisini sorgulamaktadır. Cork, R. A Bitter Truth: Avant-Garde Art and The Great War. New Haven, Connecticut (1994) günümüzde avangard sanatçı olarak düşünülen askerler tarafından açılan savaşının canlandırılması konusundaki araştırmalara yer verilmiştir. D. Delouche, ise "Cubisme et Camouflage" (1993) adlı makalesinde kübizmin kamuflaj ile olan ilişkisi ve tarihi üzerinde durmuştur. A Elias. Camouflage Australia: Art, Nature, Science and War, (2011) adlı makalesinde sanat, doğa, bilim ve askeri uzmanların II. Dünya Savaşı ile ilgili bilgileri içermektedir. Krass, P. Portrait of War: The US Army's First Combat Artists and the Doughboys' Experience in WWI (2007). II. Dünya Savaşına katılan sekiz Amerikan sanatçısının gözlemleri ve kamuflaj konuları anlatılmaktadir.

Alanyazında kamuflaj kavramının sanat ile olan ilişkisi daha çok askeri alan ve modern dönem sanatı ile ilişkilendirilmiştir. Çağdaş sanat ile kamuflaj ilişkisi Behrens'in "On Visual Arts And Camouflage" adlı makalesinde çağdaş sanatın kamuflajla olan ilişkisinin araştırılması gereken alan olduğuna vurgu yapılmakta detaylı bilgi verilmemektedir (Behrens, 1978: 204). Sanat kamuflaj ilişkisini çağdaş sanat boyutuyla ele alan araştırmacıların başında İspanyol M. Méndez Baiges'in Camuflaje: Engaño y Ocultación En el Arte Contemporaneo adlı kitabı gelmektedir. Modern ve sonrası dönem sanatında kamuflajla ilgili makaleleri bulunan yazar bu kitapta kamuflajla ilgili sanatın modern ve sonraki dönemdeki çeşitliliklerine ve etkinliklerine yer vermektedir (Méndez, 2007: 1-334). Méndez ve Pizarro'nun "Camuflajes Exhibition Catalouge" ise 2009'da İspanya'da açılan kamuflaj konulu uluslararası bir sanat sergisinin zengin resimli kataloğunu sunmaktadır (Baiges ve Pizarro, 2009:1-248). Katalogda farklı sanatçıların eserleri, yorumları yer almaktadır. Konu ile ilgili bir başka sergi kataloğu ise küratörlüğünü Ann Elias ve Nicholas Tsoutas'ın yaptığı "Camouflage Cultures, Surveillance, Communities, Aesthetics and Animal" adlı yayınıdır. Avustralya çağdaş sanatçılarının kamuflajla ilgili eserleri ve makaleler yer almaktadır. B. Richardson, Andy Warhol: Camouflage (1999). Bu Warhol'un 1986 tarihli kamuflaj resimlerinde ve ipekli ekranlarında sergilendiği bir başka sergi kataloğudur. A. Zohar'1n "Strategies of Camouflage: Depersonalization, Schizoanalysis and Contemporary Photography" (2014) adlı makalesinde görsel sanatlar alanında kamuflajı bir strateji olarak Deleuze düşüncesinden hareketle şizoanalitik açıdan yorumlamışır. "Paola Fabbri'nin "Sémiotique, Stratégies, Camouflage" (2015) adlı makalesinde bir strateji olarak kamuflajı göstergebilimsel açıdan ele alarak incelemiştir. Renaud Bouchet ise "Mémoires Du Camouflage De La Grande Guerre Dans L'art Contemporain" (2016) adlı makalesinde çağdaş sanatta dünya savaşlarının anılarına yer verilmiştir. 2019 yilında Natasha Hébert tarafindan yayımlanan makale "Camouflage Art Contemporain Africain (2019) Afrika sanatının kamuflajla olan ilişkisi çağdaş sanat boyutuyla ele alınmıştır.

Kamuflaj ile çağdaş sanat arasındaki ilişki ile ilgili uygulama ve araştırmalara 1980'li yıllardan sonra rastlanmaktadır. Bunda özellikle 1980 sonrası ortaya çıkan sosyal yaşamdaki değişim ve dönüşüm ile kamuflajın kültürel anlamda yeni bir gerçeklik olarak küresel değişimin kalıcı bir problemi haline gelmesi etkili olmuştur. Bu problem, öznenin varlığını gizleyen ve onun yerini almaya çalışan nesnenin bir metaforu olarak, sanatçıların algılarına, günlük yaşamın yeni bir gerçekliği olarak ta çalışmalarına yansımıştır. Çağdaş sanat düşünsel bir süreçten hareketle kavramları araç olarak kullanan modern sonrası dönemi refere eder. Bu kapsamda çalışma, kamuflajı bir saklanma ve gizlenme stratejisi olarak 
ele alan 1960 sonrası çağdaş sanatçıları, eserlerini ve eserlerindeki kavramsal yaklaşımları kapsamaktadır. Kamuflajın çağdaş sanat alanında modern dönemdeki kullanımından farklı bir kavram olarak ele alıp inceleyen birçok sanatçı tespit edilmiştir. Çağdaş sanat ile kamuflaj arasındaki ilişkide ortaya çıkan yeni ifade şeklini araştırmak, incelemek ve kavramsal bir temel üzerine oturtmak önem arz etmektedir. Buna bağlı olarak literatür tarama yöntemi ile kamuflaj tekniğinin tanımı, biçemi, çeşitleri, kullanım amaçları ve tarihsel süreçte gelişimi ele alınmış, çağdaş sanatçıların stratejik bir tavırla ortaya koydukları yaklaşımlar ve yaptıkları çalışmaların kavramsal bir çerçeve üzerinden sorgulanması amaçlanmıştır. Bu temel amaç doğrultusunda yapılan araştırmada, sanatın kamuflajla 20. Yüzyıl başlarında başlayan ve günümüze kadar farklılaşarak gelen ilişkisi içerisinde çağdaş sanatın kamuflajı saklanma, oyun, bedenleme, cinsiyet, kimlik ve kendisine yabancılaşma gibi kavramlarla ele alarak sanatsal ifade aracina dönüştürdükleri görülmektedir.

\section{Sanat Kamuflaj İlişkisi}

Kamuflaj ile sanat arasındaki ilişkiyi ilk gündeme getiren ve kamuflajın babası olarak kabul edilen A. H. Thayer olmuştur. Bir ressam olarak Thayer; "kamuflaj resim sanatının alanına ait olduğunu ve sadece ressamlar tarafından yorumlanması gerektiğini ileri sürmüştür. Gerekçe olarak ta konunun algı ilgili olduğunu bunun da bir ressamın yaşamının temelini oluşturduğunu belirterek Chiaroscuro tekniğini örnek olarak gösterir. Tekniğin resimdeki gibi kamuflajda kullanıldığı ve zıt etkiler yaratmak için konulduğunu vurgular (Behrens, 1978: 203).

20. yüzyıl başlarında sanatçıların orduda kamuflaj işlerini üstlenmeleri ile birlikte dönemin sanat anlayışı arasında benzerlikler görülmeye başlar. Askeri kamuflajın kaynağının, Birinci Dünya Savaşı sırasında icat edilen ve o zamandan beri tüm dünyadaki ordular tarafından sistematik olarak kullanılan bir yöntem olan Kübist anlayıştan etkilenmesi Rastlantı değildir (Baiges, 2016: 57). Birinci Dünya Savaş1 sırasında özellikle savunmaya maruz kalan Fransız askeri güçlerinin teçhizatlarına gizlemek acil bir ihtiyaç haline gelmiştir (Bouchet, 2016: 167). Bu nedenle 1914 yilında Fransa'da sanatçı Lucien-Victor Guirand de Scévola (1871-1950) ve Louis Guingot (1864-1948) tarafindan kamuflaj uygulamaları geliştirilmiştir (Coutin, 2014: 1). Ayrıca savaş sırasında André Mare, Rene Pinard, Marcel Duchamp'ın ağabeyi Raymond Duchamp-Villon gibi kübistler, bu konuda strateji geliştirmek için görevlendirilmişlerdir (Fabbri, 2015: 7). Bunlar dışında Jacques Villon, André Dunoyer de Segonzac, Franz Marc, Oskar Schlemmer, Edward Wadsworth, Arshile Gorky, László Moholy-Nagy ve Ellsworth Kelly gibi yüzlerce sanatçı dünya savaşlarında görev yaptı (Behrens, 1977). Kamuflaj konusunun giderek önem kazanması ve savaşlarda sağladığı yararlar üzerine Fransız Savunma Bakanlığ 1 , ressam Lucien-Victor Guirand de Scevola (1871-1950) ile anlaşarak 1915 y1lında kurulan ilk kamuflaj birliği ile anlaşma yaptı (Baiges, 2016: 57). 1916 yılında, İngiliz Sivil Savunma Kurumundaki altmış beş kamuflaj grevlisinden dördünün profesyonel sanatçı olması, sanatçıların bu alanda ilk kez orduda bu amaçla işe girmeleri kamuflajın sanatla ilişkisinin kurumsallaşması açısından önemlidir. $\mathrm{Bu}$ ressamlardan Norman Wilkinson'un I. Dünya Savaşı sırasında "göz kamaştırıcı gemiler" tasarladığı bilinmektedir (White, 2017: 50). Picasso; "Bu sanatçıların yaptığı kamuflaj motiflerinin doğadaki soyutlamalardan ziyade o dönemde hareketle yapıldığı ve bunun kübizm anlayışının bir sonucu olduğunu ileri sürerek kamuflajın kübist sanatçıların atölyelerinde üretildiğini "Yaptık! " diyerek dile getirir. Askeri kamuflajda kullanılan motifler ile bazı ressamların üslupları arasındaki benzerlik ile ilgili olarak yapılan röportajda Braque: "1914'te, ordunun kamuflaj için kübist resimlerimin ilkelerini kullandığını fark ettiğimde mutlu oldum” der (Behrens, 1978: 204).

Birinci Dünya Savaşı sırasında meydana gelen kamuflaj ile sanat arasındaki ilişki kübizm saflarından gelen bazı sanatçılar sayesinde avangardın sanat alanında öncü sanatçılar için kullanılmasına neden olmuştur. Sanat ve toplumun dönüşümünde öncü olarak kabul edilen "Avant-garde", askeri alanda topolojik bir metafora dönüşürken dönemin sanat alanında bir strateji haline gelmiştir (Fabbri, 2015: 910). Bu yaklaşımdan hareketle Birinci Dünya savaşı sonrası ortaya çıkan birçok akım ve anlayışta avangard biçim ve tasarımlar çok açık şekilde görülmektedir. "Mimaride, grafikte, heykel ve resim 
sanatında geleneksel olmayan sanatsal yöntem ve tekniklerin ve optik görüntünün yeniden sorgulanmasına neden olmuştur" Bu konuda öne çıkan akımlardan başında Kübizm, Fütürizm, Sürrealizm, Vortisizm ve Soyut sanat (Neoplastisizm, Suprematizm De Stjl, Abstract Expressionism, Tachism) türleri gelmektedir (Read, 1974). Cezanne, Dyolone, Mettsinger, Matisse, Derain, Boccioni, Picasso gibi sanatçılar, yeni bir sanatsal üsluplar yaratır ve çevreyi yeniden yaratmak için yeni yaklaşımlar oluşturur (Honef, 1992). Bu anlayış içerisinde askeri kamuflajlarda kullanılan motif ve desenlerin modern dönem sanatındaki gelişmelerle benzer şekilde gelişim göstermesi kübizmdeki biçim ve formun parçalanması ile Dadaizm'de kolaj tekniğinin bir uzantısı olarak görülmesi gerekir. Özellikle Kandisky gibi soyut çalışan sanatçıların resimlerindeki parçalamaların ve renk anlayışının kamuflaj tekniğinden ayrı düşünülemez. II. Dünya savaşı sırasında aktif olarak resim sanatı içerisinde soyut dişavurumculuğun somut örneklerini Pop Art anlayışı içerisinde Warhol'un kamuflaj adlı bir seri çalışmalarında ortaya çıkar. Sürrealist René Magritte, insanların kamuflajı neden sevdikleri konusunda özgün düşüncelere sahiptir. Bir radyo röportajında; "Gördügümüz her şey bir diğerini gizler; Gördüğümüz şeyin neyle ve nasıl gizlendiğini görmek isteriz. Gizlenmiş olana ya da bize gösterilmeyene bir ilgi oluşur. Bu ilgi, "görünür" ile "görünür gibi" olan arasında oldukça yoğun bir duygu, bir tür kıyas şeklinde olabilir" (Elias, 2012; 22)."De Stijl" ve Mondrian, koyu çizgilerle ayrılmış renkli kompozisyonlarla ilham verenlerinden biri olarak Alman askeri kaskları için seçilen kamuflaj ilkesinin kavramsal öncüsü kabul edilir. Daha sonra, Rus modernistleri ve özellikle Maleviç'in süpermatizmi, soyut-geometrik kavramın görsel dilini daha da geliştirdi (Tachev, 2015: 69).

İkinci Dünya savaşında ve sonra ki süreçte ortaya çıkan sanat akımları içerisinde yer değiştirme, metamorfoz ve ikiye katlama gibi kamuflaj tekniklerinin etkileri görülür. $\mathrm{O}$ dönem içerisinde ortaya çıkmış olan sürrealizmin merkezi estetik ve psikolojik eğilimleri I. Dünya Savaşı'nda geliştirilen kamuflaj taktikleriyle büyük paralellik göstermektedir. Dahası, sürrealizmin metafor ve düş gibi iki saplantısının gizlenme ve aldatma ilkeleriyle çalışması buna örnek olarak gösterilebilir (Elias, 2012: 2) Kamuflaj sürrealist dönemde askeri yerine biyolojik yönelimlerinin bir sonucu olarak taklit olarak kullanıldığı anlaşılmaktadır. ABD'deki diğer modern sanatçılar da benzer şekilde kamuflajla uğraştılar. Bununla birlikte Salvador Dali savaşta görev almamasına rağmen onun ilgisini çeken konu kamuflajın sürrealist uygulamalarla olan ilişkisiydi. 1942'de Esquire dergisinde "Total Camouflage for Total War" adlı makalesini yayımladı ve dergisini yayınladı ve "görme ya da görmemenin" nasıl olması gerektiğini önerdi (Dalí, 1942:64-67). Sürrealist görselliğin ikiye katlama dünyasına ve resim ve hayallerinin paranoyak ve yerinden edilmiş görüntülerine kıyasla doğa ve savaşta taklit etmenin ne kadar cazip olduğunu düşünmeye zorlandı. Dalí, sürrealizme "karışıklık sistemizasyonu", savaşta kamuflaj için de aynı şekilde uygulanabilir görünen bir açıklama olarak adlandırdı ve I. Dünya savaşında kamuflaj ne kadar kübist bir tavır benimsediyse II. Dünya savaşında da Sürrealist bir tavır benimsemelidir. Çünkü bu daha çok bu dönemde kamuflajın sırrının fiziksel değil psikolojik olması gerektiğini öne sürmüştür. 1943 'te Arshile Gorky, New York'taki kamuflaj üzerine bir sivil savunma manifestosu yazdi. Bu manifestoda, düşmanın vizyonunu felce uğratmanın gerekliliği tartışıldı (Elias, 2012: 18).

\section{3. Çağdaş Sanatta Kamuflaj Stratejileri}

II. Dünya Savaşı sonrası, değişen politik dengeler ve küreselleşme ile beraber kültür politikalarının da küreselleşmesine, yeni kültürel alanların ve tanımların çeşitlenmesine dolaysıyla sosyal yaşamın değişmesine neden olmuştur. Sosyal yaşamda ortaya çıkan bu değişikler ve beklentiler bireylerin estetik ve kültürel anlayışlarını da değiştirmiştir. Özellikle teknoloji, kültürel ve sosyal yaşam koşulları her geçen gün sanat dinamiklerinin biçimlenmesine ve yaratım sürecine yön vermeye başlamış, disiplinler arası yeni yaklaşımların ortaya çıkmasına neden olmuştur. Bu yaklaşımlara bağlı olarak sanat alanında da yeni yaklaşımları ortaya çıkmıştır. Ortaya çıan bu yaklaşımlar içinde sanatçılar, performanslar, yerleştirmeler, kavramsal işler, video, beden sanatı, resim, fotoğraf aracıllğı ile gerçeği yansıtma ya da kendini ifade etme çabasında olmuştur. İroniler, metaforlar, pastişler ve eklektik nesneler yoluyla izleyiciyi manipüle etme ve yanıltma amacı gütmüştür. Sanatçı sadece biçimsel bir temsil yerine 
izleyicinin eser ile karşılıklı etkileşime girmesine ve oluşacak algısal farkl11ıklarla yeni bir düşüncenin oluşmasına neden olacak olan işlerin tasarımına yönelmiştir. Bu tasarımlar içinde gerçeklik ve yanılsama kavramlarını aynı anda içerisinde barındıran kamuflajın da modern sonrası süreçte kullanılan bir strateji haline gelmesine neden olmuştur. Özellikle altmışlı yıllardan sonra ortaya çıkan sosyal yaşamdaki değişim ve dönüşüm ile kamuflaj kültürü yeni bir gerçeklik olarak küresel değişimin kalıcı bir problemi haline getirmiştir. Bu problem öznenin varlığını gizleyen ve onun yerini almaya çalışan nesnenin bir metaforu olarak sanatçıların algılarına, günlük yaşamın yeni bir gerçekliği olarakta çalışmalarına yansımıştır. 1960 sonrası çağdaş sanat uygulamalarında kamuflaj bazen oyun olarak, bazen bedenleme, bazen de cinsiyet ve kimlik stratejisi olarak gizlenmenin ve yanılsamanın fiziksel, görsel ve psikolojik ifadeyi de ele alan kavramsal bir temel üzerine yoğunlaşmıştır. Bu süreçte kavram ile ilgili birçok sergi açılmaya ve yayın yapılmaya başlamıştır. Bu kapsamda Alain Jacquet, 1961'den 1964'e kadar kamuflajı sanatsal yaratma bağlamında ele aldı ve renkli formları üst üste ya da yan yana koyarak resimsel yüzeyleri modern dönemin birer temsili ve hatta ikonik eserleri haline getirmiştir. Bunlar Pop Art'ı temsil eden çalışmalardan oluşmaktaydı. Henri Matisse'in Luxe'i, Calme et Volupté (Görsel 1) ve Roy Lichtenstein'ın Little Aloha'sı Görsel 2), (1963 ve 1964). Bunların ilk örneğini oluşturur (Bouchet, 2016: 167).

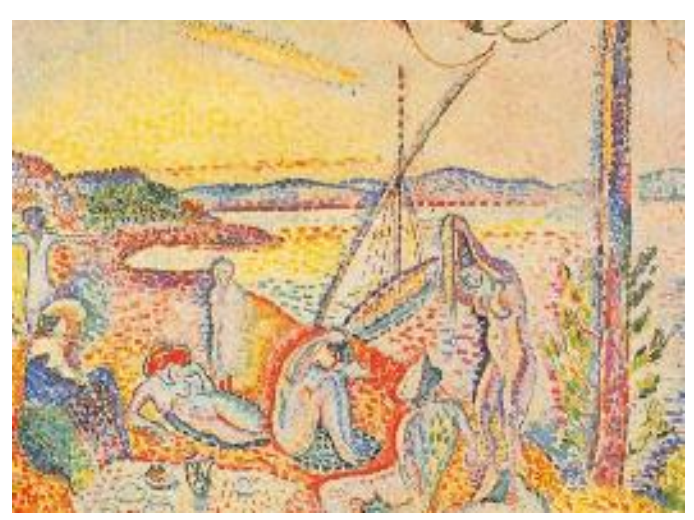

Görsel 1. Henri Matisse, Luxe, Calme Et Volupté, 1904, Tuval Üzerine Yağlıboya, 94X116, Orsay Müzesi, Paris.

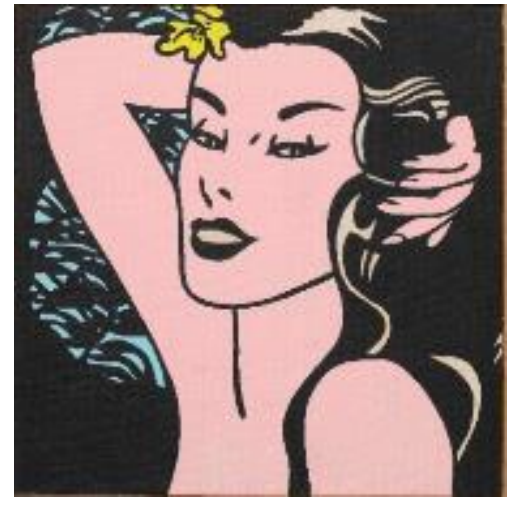

Görsel 2. Roy Lichtenstein, Little Aloha, 1962, Tuval Üzerine Akrilik ve İpek Baskı, 16.5 x $16.5 \mathrm{~cm}$.

1966'dan 1968'e kadar Pierre Buraglio, Piet Mondrian'ın neoplastikçi geometrik resmini taklit eden "Kamuflaj Egzersizleri" ile benzer bir yaklaşım izlemiştir. 1980'lerde, Mayıs 1964'te New York Iolas Galerisi'nde düzenlenen Camouflages de Jacquet sergisinin ziyaretçileri arasında Roy Lichtenstein ile anılan Andy Warhol, aynı zamanda özerk bir süreçte kullanılan kamuflaj motifini de kullanmıştır.

İkinci Dünya Savaşı'ndan sonra savaş karşıtı protestocular çatışma ve savaşta silah ve silah kullanımına karşı protestolarını ifade etmek için askeri kıyafeti kullandılar. Özellikle Amerika'nın kendi toprakları dışında savaşlara katılımı, yirminci yüzyılın ortalarında Andy Warhol'un da içinde olduğu birçok sanatçının eserinde bir protesto haline gelmiş̧ir. Warhol kendisini soyut dışavurumculuktan uzak tutmayı hedeflerken motiflerinin zamanla geniş bir şekilde tanınabildiği ve yeni anlamlar kazandığı, Amerikan resminin yakın tarihi ile özdeşleşen soyutlamanın içerisinde bulduğunu söyler. Bu konuda Warhol'un asistanlarına "Ne yapabilirim ki bunlar soyut ama soyut değil" dediği anlatılır (Warhol, 2018). 


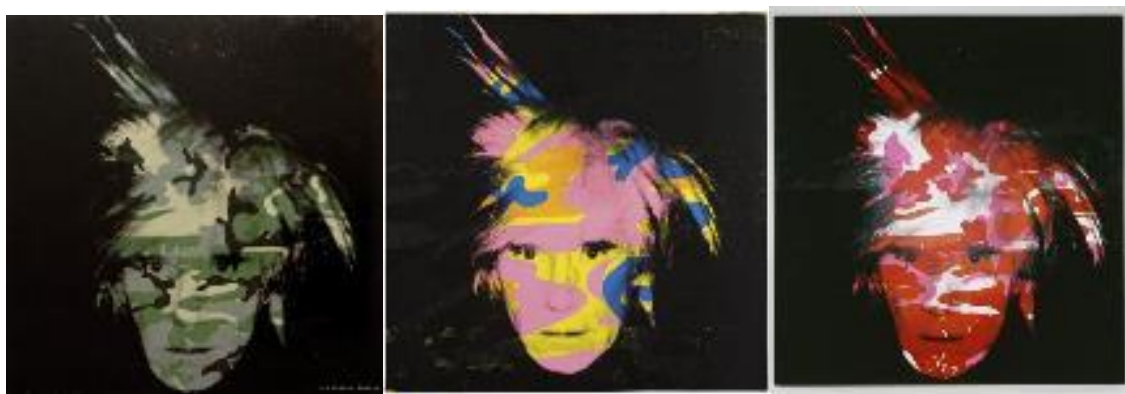

Görsel 3. Andy Warhol, Camouflage Self-Portrait, 1986, Tuval Üzerine Akrilik ve Mürekkep, 101 X 101.cm.

Kamuflaj malzemeleri Andy Warhol'a hem soyut bir motif hem de somut bir imajın birlikteliği açısından farklı bir çalışma fırsatı vermiştir. Kamuflaj çalışmalarında parlak sentetik ve inorganik renkleri tercih eden Warhol, çeşitli ölçeklerde ve geniş bir renk yelpazesinde birçok kamuflaj paneli üretmiştir. Serigrafi işlemi hızlı ve kolay seri üretim için izin verdiği için Warhol, "Kamuflaj SelfPortrait" (Görsel 3) tuval üzerine yerleștirmiștir. Metropolitan Sanat Müzesi'nde solgun yüzü ve saç1 siyah, gri ve yeşilin siyah bir arka plan üzerinde askeri bir kamuflaj deseniyle kaplıdır. Kamuflaj deseni, figür ve fon arasındaki ilişkileri karıştırarak kendi hayatının bir metaforu olarak yorumlanan bir kamuflaja dönüşmüştür (Pettersson, 2018 11-12). Bu portrelerinde ile askeri motifleri kullanmas1 sanatçının kendi özel hayatını kamufle ederken, kötü şöhret elde etmek için yaşam boyu süren mücadelesini de ortaya koyar. Warhol yaptığı çalışmalar ile askeri bir malzemenin işlevini ortadan kaldırır ve kamuflaj kavramını yeniden yorumlamak için renk ve biçimleri manipüle ederek onlarla oyun oynar.

1960 ve 70'li yıllarda sanatçılar kamuflajı daha bağımsız şekilde ele alarak kavramsal ağırlıklı işler üretmeye başlamışlardır. Bu anlamda Alighiero e Boetti, Savaş sonrasında artakalan malzemelerle farklı sanatsal yöntemler kullanan Art Povera sanatçılarından birisidir. Boetti, çağdaşlarının çoğunda olduğu gibi, önceden var olan görüntüleri ya da atık malzemeler kullandı; Ticari tükenmez kalemleri, halının biçimini, pullarını, zarflarını, haritaların yanı sıra veya kamuflaj desenlerini bu gündelik eşyalardan birisiydi (Watson, 2009: 297).

Görsel taklit ile kamuflaj arasındaki ilişki için 1960'larda, kavramsal sanat doğduğunda, Alighiero Boetti Mimetico adlı bir eser yaratmıştı. Bu resimde 1950 İtalyan ordusunun kullanmadığı bir kumaş parçasını bit pazarından satın alarak dönüştürmüştür. Bu Warhol'ün yaptığı çalışmalardan biçim açısından hiç te farklı değildi.

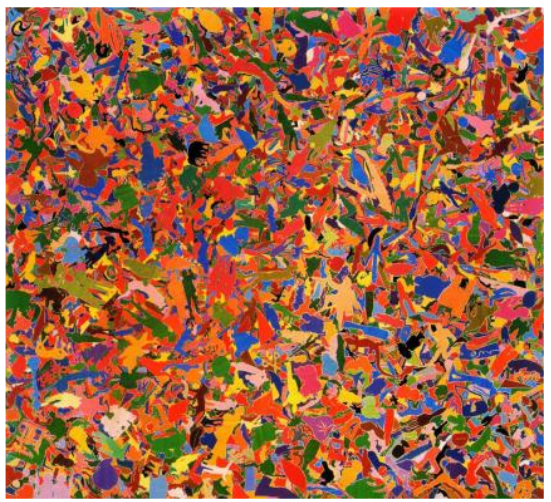

Görsel 4. Alighiero Boetti, Tutto, 1988-1989, Nakış, $231 \times 212 \mathrm{~cm}$

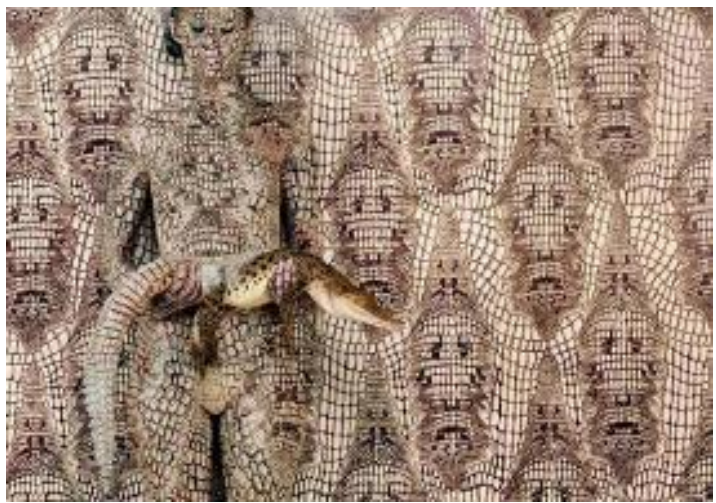

Görsel 5. Emma Hack, Evolution Crocodile 2008, CPrint, $120 \times 90 \mathrm{~cm}$, 
Boetti Duchamp'ın hazır nesne fikrini 60'lı yıllarda kullanarak kamuflaj kumaşının soyut bir tasarım olma özelliğine sahip olan nesne olduğunu ortaya koymuştur. Askeri kumaşın üzerindeki motiflerin belirsizliğindeki derin oyun: soyut bir şekiller ve renklerin doğadan alınan bir bilişimidir. Tutto (Görsel 4) adlı çalışmasında Afgan kadınlarının seçtiği renk ve ipliklerle yapılmış olan çalışmada farklı nesneler ve hayvanlar bir bulmacadaki gibi, çok renkli parçaların oyunundan oluşan bir kompozisyondur (Baiges, 2016: 64).

Sanat, 1960'larda temsiliyet konusunda oldukça dramatik dönüşümlere sahne olmuştur. Sanatın ne olduğuna ilişkin geliştirilen dil ve estetik sorgulamalar ile dönüşen yapıt, onu anlamaya kaynaklık eden tüm teorileri de altüst etmiştir. Bu anlamda modern sonrası sanat ve düşüncenin post yapısalcı kavram ve olgularla birlikte düşünülmeye başlamıştır. Bu süreç performans ve fotoğraf üzerinden, beden, kimlik, post-feminizm, cinsiyet politikaları gibi son dönemlerin tartışmalı sorunlarını incelemekte, kimlik eksenli tartışmaların, feminist söylemin, beden politikalarının modernist düşüncesinden sıyrılarak, travmatik bir morfolojiye bürünmesine zemin hazırlamıştır (Esmer, 2015). Çağdaş performans sanatı içerisinde Avusturalyalı Emma Hack, kadın bedenini cinsellik boyutuyla sorgulandığı çalışmalarında kamuflajı bir strateji olarak benimseyen sanatçılardan birisidir. Tüketim kültürüne özgü her tür nesneyi, cinsellik boyutuyla ele alan Hack, model kullanarak onların bedenlerini kendine özgü motiflerle boyar. Arka planda bulunan fon için evlerde kullanılan duvar kağıtları önüne yerleştirdiği modelini fonda bulunan motiflere göre tekrar boyayarak yapar. Bunu doğadaki motiflerden ya da süslemelerden yola çıkarak değil, kendine has geliştirdiği ya da Avustralya kültürüne ait motifleri bir çıkış noktası olarak alır. Çalışmalarını daha çok fon olarak seçtiği duvar kağıtları önünde canlı kadın bedenleri üzerine saatlerce çalışarak işlerini tamamlar. Bu çalışma hem fon ile bütünlüğü hem de kaynaşma ve kamuflaj açısından oldukça zor ve yorucu bir süreci gerektirir. Sanatçı modellerini tamamıyla çıplak ve güzel kadınlardan seçerek biçimsel görünüm ile cinsellik temasını örtüştürmeyi amaçlamaktadır. Kadının toplumdaki yeri ve statüsünün ötesinde cinsel bir arzu nesnesine dönüştürülmesini, arka planda sakladığı/ gizlediği kimliğinin oluşturduğu bir zıtlıkla gerçekleştirir. Bu paradoks modelin eline ya da yanına yerleştirdiği bir kanguru, timsah, bebek oyuncak bir ayı gibi nesli tükenmekte olan canlılar ile gerçekleştirilir (Görsel 5).

Çağdaş sanat uygulamaları içerisinde cinsiyet kimlik ve mekân konularını kullandığı farklı tekniklerde (video, film, enstalasyon, fotoğraf) kamuflajı bir strateji olarak kullanan Lalla Essaydi (Fas, 1956) Arap kültürüne ait kadınlarının kimliklerine ilişkin, kişisel deneyimlerine dayalı çalışmaları ile bilinmektedir (Görsel 6). Kadınların kapalı iç mekânlardaki fotoğrafları 'Kadın' kavramının erkek egemen toplumlardaki ve erkek gözünden alg1 ve beklentilerini simgelemekte, Arap kültürünün etkin olduğu geniş bir coğrafyanın görsel verileri ile şekillenmektedir. Fotoğraflarını kısmen otobiyografik olarak değerlendiren Essaydi, bir kadın olarak hem batılı hem doğulu kimliğinin, geçmişte ve bugünde varoluşunun deneyimlerinin sonucu olarak tanımlamaktadır (Özdal, 2013, 70). Essaydi, Arap kadın kimliğine atıfta bulunmak ve kendi geçmişini ve kökenini sorgulamaya yönelmiştir. Böylece batı toplumlarındaki arzu ile ilgili kalıplaşmış değer yargılarını yok etmeye çalışır. Özellikle batı oryantalizmi içerisinde harem, hamam ya da odalıklarda cinselliği, şehveti ve arzuyu temsil eder şekilde çıplak betimlenen doğulu kadınların içinde bulunduğu durumu sorgular. Essaydi, fotoğraf çalışmalarında farklı mekân ve ortamlarda kadınları geleneksel bir diyalog içerisinde betimler. Bunu büyüdüğu kültür içerisinde yer alan kadın kıyafetleri ile mimaride kullanılan motiflerin benzerliğinden yola çıkarak yapar. Kadın bedenlerine kına ile yazdığı Arapça yazı ile kamufle eder. Kınanın boya malzemesi olarak seçilmesi ise kadınların geleneksel anlamda süs amacıyla kullandıkları bir malzeme olmasından kaynaklıdır. Kına doğulu kadınlar için en önemli süs aracı olarak etkisini hala sürdürmektedir. 

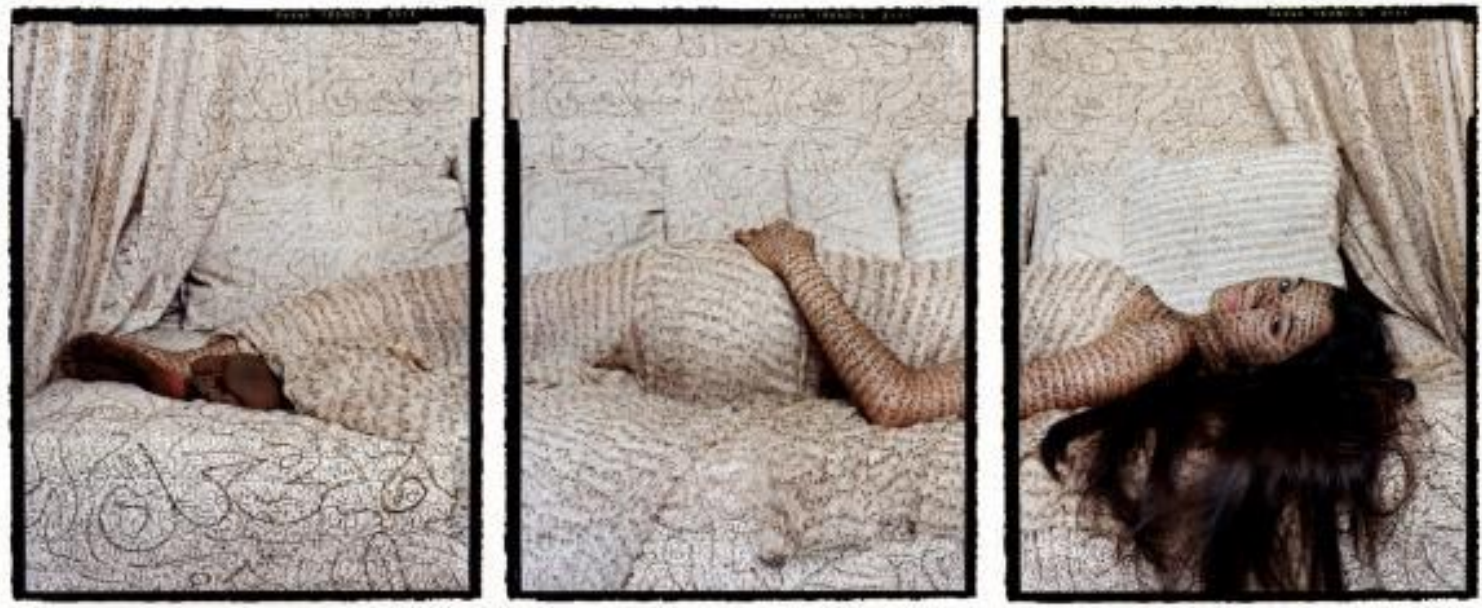

Görsel 6. Lalla Essaydi, Les Femmes du Maroc, Harem Beuty, 2008, Aliminyum Bask1, 122 X76 cm

Essaydi bir röportajında çalışmalarındaki kimlik ve cinsellikle ilgili olarak; "özel ve kamusal alanları Müslüman kadının cinsel kimliği belirlemektedir. Doğulu kadınlar geleneksel olarak özel bir alana işaret eder ancak bir kadın nerede olursa olsun, bir erkek o alana girdiğinde mekân kamusal alana döner. Özel alan ile kamusal alanının bu ayrılı̆̆ı kadınların cinselliğinin bir göstergesidir. Ayrıca batının oryantalist bakış açısı içerisinde kadının nasıl cinselleştirildiğini gösterir" demektedir (Errazzouki, 2012). Sanatçının çalışmaları, geçmiş ve günümüzün doğu kültürü ile batının algılaması arasındaki fark1, ya da kadının toplumsal konumu ile sosyal rolünün yorumlamasındaki farkı ortaya koyar. Konu olarak seçtiği kadını belli bir kamuflaj altında göstermek etkiyi daha da belirgin hale getirerek görünmeyeni yeniden görünür hale getirmektedir (Brielmaier, 2006: 90-91).

Sanatçılar modern sonrası toplumların baskıcı ve müdahaleci bir kontrolün altında özelliklerini vurgulamak için eleştirel bir söylem olarak kamuflajı bir sanatsal strateji aracı olarak farklı kavramlarla birlikte kullanmaktadırlar. Sanatçıların etik ve estetik açıdan kamuflaja yönelmeleri günümüz toplumların değişen yapısını ironik olarak vurgulamak amacından kaynaklanmaktadır (Fabbri, 2015). Desiree Palmen gibi sanatçılar toplumdaki bu değişimi sokak kameralarıyla gerçekleşen gözetleme ve izlemeye karşı bir tavır olarak kamuflajla ironik hale getirmektedirler (Görsel 7) Palmen yaptığ1 çalışmalarda kamuflajın ne anlama gelebileceğini sormamızı istiyor. Bu insanlar olumlu ya da olumsuz nedenlerle neden saklamak isterler? Ve bu tür soruları göz önünde bulundurarak, internette gizlice dolaşırken neden gerçek kimliğimizi gizlemek isteyebileceğini düşünmeye davet ediyor. Palmen'in çalışmalarının çoğunda birey ile içinde bulunduğu ortam arasındaki ilişki hakkında soru sormak için kamuflajı fiziksel, sosyal ve politik bir metafor haline getirir (Pratt, 2007). 


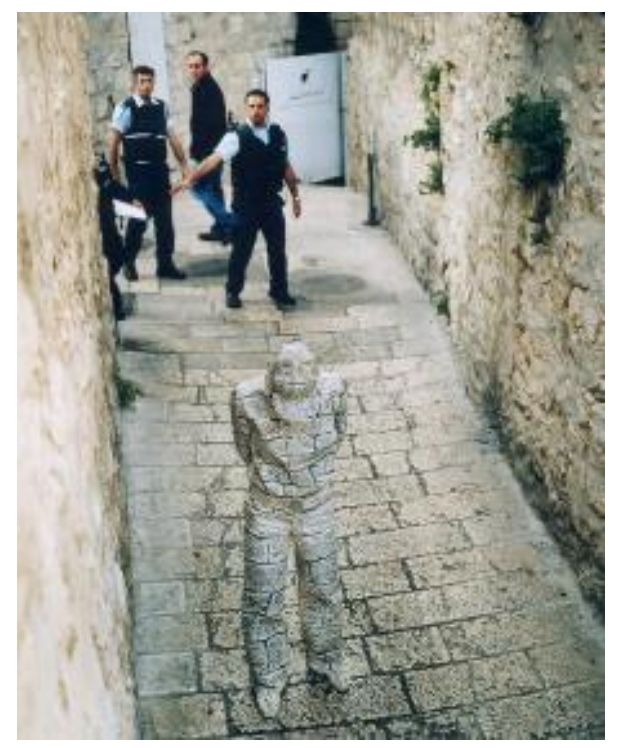

Görsel 7. Desiree Palmen, Police Camera Christian Quarter, Polis kameras1, 2006, 92x70 c

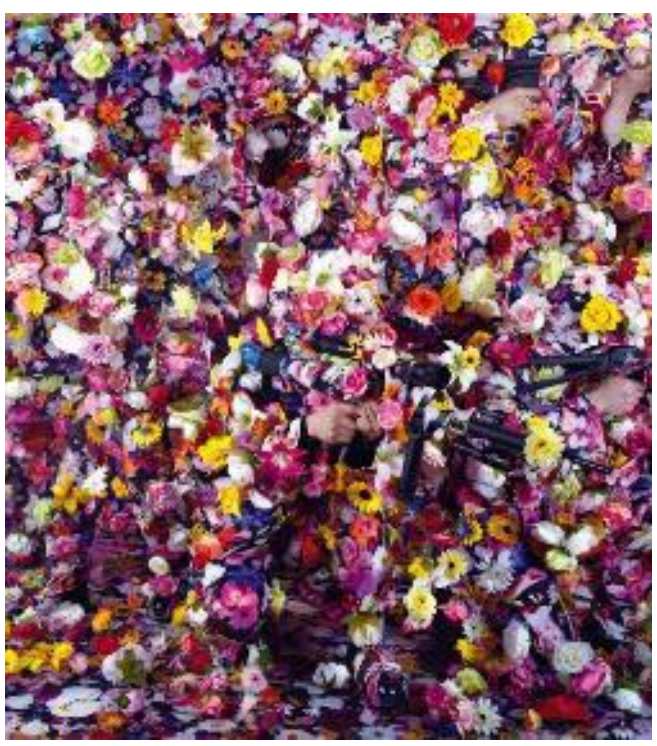

Görsel 8. Lee Yong Baek, Angel-Soldier Version 23 dk video, 2011,

Çağdaş sanatçılar, 80'li yıllardan sonra kamuflajı etik ve estetik açıdan daha rafine bir şekilde tanımlarlar. Baudrillard'ın deyimiyle, bir temsil (representation) kültürü değil bir taklit (simulacrum) kültürü olan modern sonrası kültürün içinde gelişim göstermeye başlamıştır. (Bauman, 2000: 142-143). Toplumsal yapıya özgün kimlik, siyaset, din gibi konuları etkin bir şekilde sorgulayan çalışmalar yapan Lee-Yuong Beak (Kore,1966) çalışmalarının kabul görmesinin nedeni sadece teknolojik çalışmaları değil, çağımızın politik ve kültürel sorunlarını teknoloji ile hayal gücünü birleştirme yeteneğinden kaynaklıdır. 2011 yılında katıldığı Venedik Bienalinde heykel, resim, video çalışması ve baskıları yer aldı. Kore pavyonundaki Serginin en önemli işi kamuflaj çalışması "Angel Soldier" (Melek Asker) de ön planda, çiçek motifli bir panoya yerleştirilmiş büyük motif baskılar bulunur. Bu motifler askerlerin üzerinde bulunan kıyafetlerle aynı şekilde tasarlanarak kamufle edilmiştir. Bu yerleştirme yanında bir video çalışmasıyla aynı konu üzerine odaklanan "Angel Soldiers" (Görsel 8) adlı video işi yirmi üç dakikalık bir sunumundan oluşmaktadır. Bu işinde melek ve asker arasındaki şiddetli kontrastı ile, herhangi bir mantıksal işlem ve açılama olmaksızın, dönemin toplumsal koşullarını doğrudan ve açık bir şekilde ifade eden bir video performansıdır.

Modern sonrası dönemde sermayenin küreselleşmesi ile öne çıkarılan tüketim kültürü, her şeyin tüketilebilir bir deneyim olarak sunulabilmesini sağladı. Doğal olarak da bu tüketimin kentlerde çeşitli şekillerde pazarlanmasıyla öne çıkarıldığı görülmektedir. Sanat, bu pazarlama stratejisinde 'gündelik hayatın estetikleşmesi' ve 'aurasından yararlanılması gereken' bir rol üstlenmiştir. Festivaller, bienaller, fuarlar, kamusal mekân ve kentsel dönüşüm projeleri, kentleri adeta yeniden yaratmakta ve biçimlendirmektedir (Esmer, 2015). Liu Bolin, (Çin, 1973) ekonomik ve siyasi gidişatın, insan sağlığını hiçe sayan endüstriyel gelişimin, yozlaşan medyanın, devletlerin katılaşan kontrol mekanizmalarının insan üzerindeki etkisini özgün bir dille görselleştirmektedir. Bireyin değersizleştirildiği ve yalnızlaştırıldığını göstermek amacıyla kendini model olarak kullanmaktadır. Bunu asistanları yardımıyla ve herhangi bir grafik programı kullanmadan bedeni üzerinde yaptığı motiflerle performansa dönüştürmektedir. Genellikle arka kısımda kullandığ 1 günlük yaşamdan alınmış tüketim nesneler önünde kendisini saatler süren bir boyamadan sonra kamufle eder. 


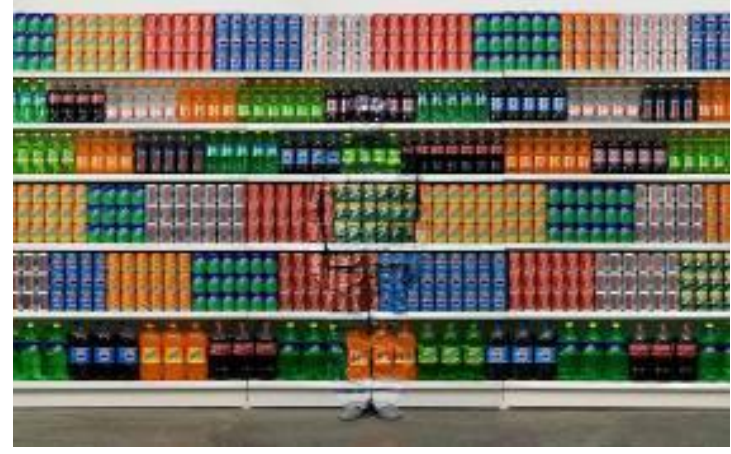

Görsel 9. Liu Bolin, Hiding in the City No. 93 Supermarket No. 2, photograph, $118 \times 150 \mathrm{~cm}$

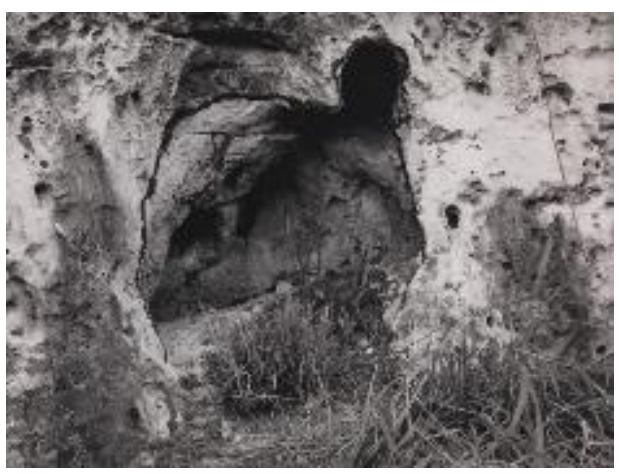

Görsel 10. Ana Mendieta, Untitled, 1981, Photography lifetime black and white photograph 20.3 $\times 25.4 \mathrm{~cm}$

Bolin saklar, kendisini kendisinden ve Tanrı'dan saklayarak maddi kültür ile bütünleşir. $\mathrm{Bu}$ sanatçının duyarlı olması ile ilgilidir. Ona göre, eğer sanat susarsa, toplumun ölümü demektir. Yani, toplumun en büyük sığınağı sanattır, sanatçının özgür ifadesidir. Bolin, kamuflaj kavramı içinde eleştirel bir tavır benimsemesi, algıların bireydeki oluşturduğu farklı etkileşim tiplerinin de tepkisel sonuçlarını ölçümlemektedir. Yaşamın içindeki nedenleri ve oluşun getirdiği kaygı aynı zamanda gizlenmenin ya da izole olmanın diğer bir yönüdür. Sanatçı mekân içindeki gizlenmede kaygının getirdiği bir yorumu sunmaktadır. (Gültekin, Peker, 2016: 165). "Hiding in the City No. 93 Süpermarket No. 2 " adlı çalışması (Görsel 9) tüketicilere sonsuz seçenekler sunma kabiliyetine sahip, çeşitli batı markalarının özenle hazırlanmış içecekleriyle dolu bir süpermarket rafının bir bölümünü sunmaktadır. Tüketebilme özgürlüğü buradaki yeni slogandır. Her zaman arzu edilen, modern ve kentli olmak, şimdi tüketici olmak olarak yorumlanmaktadır. Dahası, tüketen insanlar ideolojik olarak üstün ve toplumun daha aktif ve arzu edilen üyeleri olarak görülüyorlar (Zhao ve Belk 2008: 237).

Kimlik cinsiyet çağdaş sanatın ilgilendiği en belirgin konuların başında gelmektedir. Her türlü nesne ve doğal mekânı birlikte kullanan görsel ve gösteri sanatlarında "beden" ana konudur. Sanatçılar kendi bedenlerini doğa ile harmanlar ve kendilerini doğanın öğrettiği gibi kamufle eder. Beden sanatı ve performansla ortaya çıkan etkinlikler içerisinde kendi bedeni ile doğada formlar ve deformasyonlar üreten Ana Mendieta (Küba, 1948) doğaya bıraktığı beden izlerinin kaybolması ile boş bir şablona dönüşür zamanla kaybolur ve silinerek yok olur. Mendieta, Silueta (Görsel 10) dizisinde kendi bedeninin bu kamufle olma sürecini belgeleyerek eser üretmektedir.

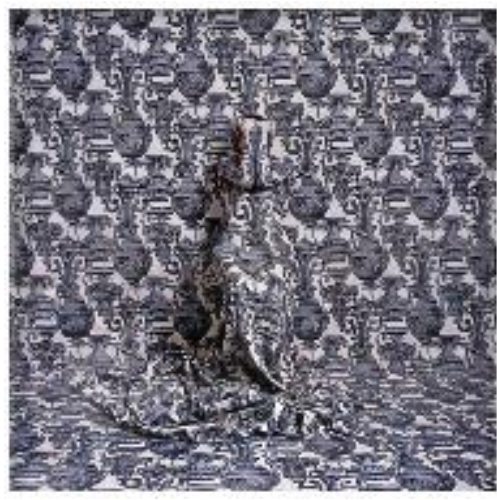

Görsel 11. Cecilia Paredes, Corinthians, 2014, dijital Fotoğraf $120 \times 120 \mathrm{~cm}$

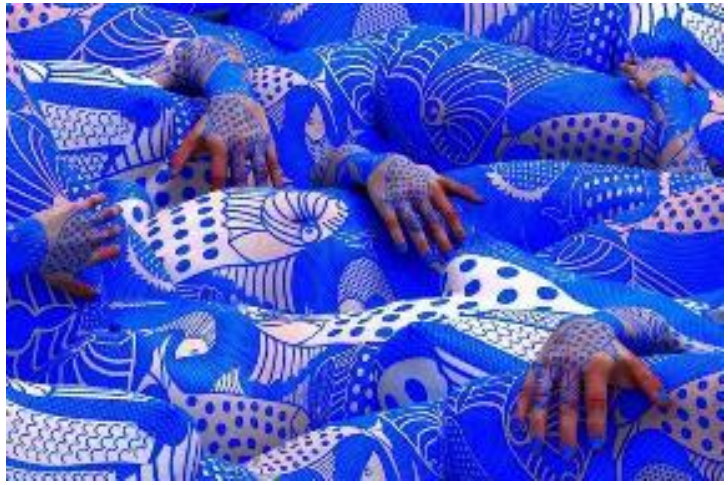

Görsel 12. Kim Joon, Blue fish, 2008, photographs, cprint, $101.6 \times 101,6 \mathrm{~cm}$. 
Cecilia Peredes (Peru, 1950) kendi vücudunu çeşitli motiflerle boyayarak kamufle etmekte ve bunları fotoğraflamaktadır (Görsel 11). Bedenini tuval olarak kullanarak ormanlar ve çöllerin ve bitkisel motiflerin önünde kendi bedenini boyayarak çalışmalar üretir. Sanatçı çalışmalarıyla ilgili olarak; "Bizi insan yapan şey, dünyaya geldiğimiz bu kültür dışında diğer kültürleri, diğer yaşam kalıplarını tanıyarak kültürümüzü aşmaktır. Yine de kendi kültürümüz ile var oluruz. Kimliğin gizemi asla tam olarak çözülmez. Asla geri dönemeyeceğimiz bir zaman ve yerdeyiz" (Peredes, 2018). Bedenleri kullanarak performans yapan başka bir sanatçı Kore'nin en saygın genç sanatçılarından olan Kim Joon'dur. (Kore, 1984). Dijital ortamda porselen ve dövmeler kullanarak arzu, bellek ve gençlik temalarını inceleyen dijital baskıları ile bilinmektedir. Konuları, idealize edilmiş kadın bedenlerinden, gitarlardan, arabalar ve silahlar da dahil olmak üzere Batı pop kültürünün ikonlarından seçilmiştir. İşlerinde bedeni bir kamuflaj aracı olarak kullanarak tüketici kimliğinin kurgusal bir alanına işlemesine imkân veren ve motifleri emanet katmanlardan oluşturan yapıya büründürmektedir. Joon'un çalışmaları, özellikle boyadığı modellerini reklam panolarının çağdaş kentsel manzaraları ile ilişkilendirir. Ancak geleneksel temalarla boyanan bedenleri arka plan ile kaynaştırarak kamufle ediyor bunu yaparken de özellikle kusursuz bedene sahip modellerden yararlanır (Görsel 12).

Çağdaş sanat, sanatçıların kuramları ve ideolojik eleştirisiyle içyüzünü açığa çıkartma iddiasında bulunduğu gündelik gerçeklik kadar sıradan görünür (Kuspit, 2010, 111). Toplumsal olayları kamufle ettiği motifler arasına yerleştirdiği sembollerle ironik bir şekilde eleştiren İranlı sanatçı Parastou Forouhar (İran, 1962), fotoğrafçıllı̆ından dijital çizimlere ve çoklu ortam kurulumlarına kadar çok çeşitli tekniklerle anavatanındaki şaşırtıcı olaylara tepkisini ortaya koymaktadır. Forouhar, Hat ve minyatür gibi geleneksel İran sanatlarında bulunan kültürel değerleri kullanarak, bu formların güzellik ve kültürel kimliğin standartlaştırılmış bir anlayışına bağlı kalarak üretim yapmaktadır. Bunu çalışmalarında tamamıyla belli bir süsleme düzeni içerisinde gerçekleştirir. Herhangi bir eski İran minyatürünün dünyanın küçük, idealize edilmiş bir aynası olduğunu iddia eder. Ancak bu süsleme ile radikal ve bağnaz köktendincilerin tek boyutlu, basit ve popüler dogmaları arasındaki paralellikleri ortaya koyar. Yapıtlarının bir kısmı, kamuflaj benzeri figürlerin neredeyse tamamen çevreye karıştığı dijital olarak dönüştürülmüş çizimlerdir. Resimdeki görüntüleri algılamak için sadece eller ve kafalar farklı yönlerde kullanılır. Belki de çevrenin erimesi, bir kişinin ya da bireyin kaybıdır ya da günlük yaşamlarını yaşayan ve tamamen kişiliğe saklanmayan kadınların durumudur (Görsel 13). Sanatçı çalışmalarında kullandığ ya da ele aldığı objeleri birer metafor olarak kullanır. Metaforlar süslemenin başka bir yönünü oluşturur aslında. Siyasi ve dini baskılara ve yasaklara karşı metaforlar sanatçıların kamufle edilmiş ifade araçlarına dönüşür.

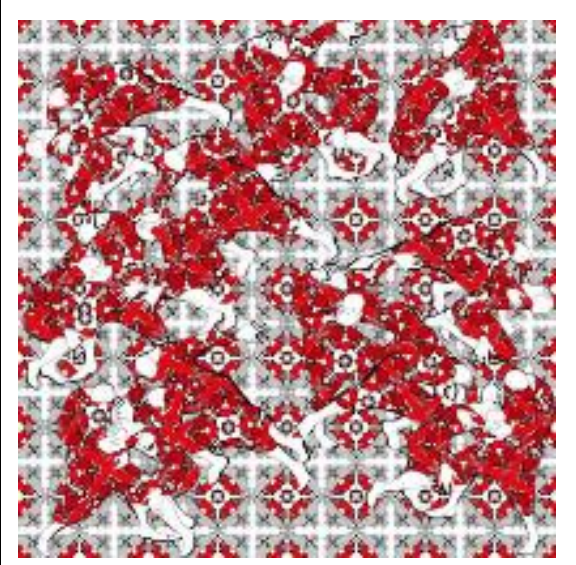

Görsel 13. Parastou Forouhar, Red Is My Name, Green Is My Name III, 201, Eski Fotoğraf Üzerine Dijital Çizim, $80 \times 80 \mathrm{~cm}$

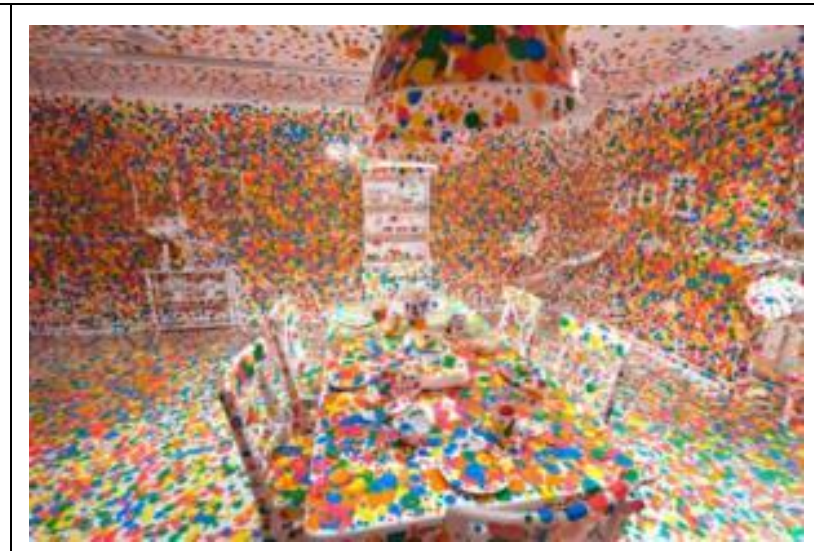

Görsel 14. Yayoi Kusama, The Obliteration Room, 2002, Yerleştirme, Queensland Sanat Galerisi. 
Yaşayan en önemli kadın neo-avangart sanatçılardan birisi olarak kabul edilen Japon sanatçı Yoyoi Kusama (1929) en basit motif elamanı olan noktayı kullanarak mekân yerleştirmeleri yapan bir sanatçıdır. Kusama'nın halüsinasyonları ve kişisel takıntıları, onun kendine özgü üslubunu yaratmasındaki en önemli çıkış noktasını oluşturur. Kusama'nın çalışmalarında en önemli unsur renkli noktaları birer motif elemanı olarak mekân içerisinde tekrarlaması ile oluşturduğu atmosferdir. Resim yanında performans, enstalasyon sinema gibi farklı alanlarda da yürüten sanatçı ağırlıklı olarak enstalasyonları ile tanınmaktadır. Çalışmalarına baktığımızda tüm evreninizin kırmızı puantiyelerle kaplandığına tanık oluruz. Mekanları gizlenme ve kamuflaj için tasarlanmış gibidir çünkü dünya tehlikeyle doludur. Böyle bir tehlikeye karşı bariz bir savunma, kendini bir şekilde görünmez kılmaktır. Kusama'nın çalışmalarından birisi olan çocuklar için tasarladığı "Silinmişlik Odası" (Görsel-14) buna en iyi örneklerden biridir. Bu oda ilk başta hiçbir renk barındırmaz; duvarlar, tavan, zemin, içerisindeki tüm eşyalar dahil her şey düz beyaz renge boyanmıştır. Ziyaretçiler kendilerine verilen yuvarlak formdaki farklı boyut ve şekillerde renkli yapıştırmaları odada seçtikleri herhangi bir yüzeye yapıştırır. Etkinliğin sonunda oda Kusama'nın deyimiyle "silinmiş" olur. Kusama'nın özellikle çocuklar için yapmış olduğu bu çalışmada kendi çocukluğunda yaşadığı travmaların etkisi olduğu söylenebilir.

\section{Sonuç}

Kamuflaj, yaşadığımız çağda biyolojik ya da askeri bir terim olmanın yanında hem bireysel hem de sosyal bir kaygının yeni bir söylemi olmaya başlamıştır. Kamuflajın günümüzde önemli bir söylem ve stratejik bir kavram haline gelmesinde en önemli etken iletişim araçlarının bireyin ve toplumun değişimi üzerinde oynadığı roldür. Özellikle modern sonrası çağda gelişen kitle iletişim araçlarının günlük yaşamımızın bir parçası haline gelmesiyle hiçbir "gizliliğimizin" kalmadığı, gelişen teknolojilere ayak uydurmadığımızda ise "görünürlüğümüzün" kaybolduğu çağda, kamuflajı bir stratejik kavram olarak algilamak, görece daha kolay olsa gerek...

Sanat günümüzde toplumsal gelişmelere bağlı olarak temsiliyet açısından radikal dönüşümlere sahne olmuştur Günümüzde sanatın ne olduğuna ilişkin geliştirilen dil ve estetik sorgulamalar ile dönüşen yapıt, onu anlamaya kaynaklık eden yaklaşımlar nedeniyle kavram ve olgularla birlikte düşünülmeye başlamıştır. Bu anlamda kamuflaj çağdaş sanatın yeni bir söylemi haline gelmiştir. Bu, öznenin varlığını gizleyen ve onun yerini almaya çalışan nesnenin bir metaforu olarak sanatçıların çalışmalarına yansımıştır. Çalışmalarında deneysel bir yaklaşım sergileyen sanatçılar, gerçeklik kavramlarından hareketle kamuflajı bir illüzyon olarak kullanmışlardır. Kamuflaj çağdaş sanat içerisinde; öznenin gerçek görüntüsünü, kimliğini ya da duygularını, gerçek amaçlarını, sadakatini, samimiyetini, acı ve sevincini oluşturan değerleri, yanılsama/illüzyon yoluyla manipüle ederek izleyiciyi yanıltır. Bunu yaparken de çok farklı metaforlar kullanır. Bu metafor bazen özneyi mekâna, bazen de mekânı özne yerine koyarak gerçekleşir ve özne olduğu değil olmak istediği bir yeni bir gerçekliğin parçası olur. Özne burada tam olarak yok olmaz, gerçeklikten uzaklaşarak kendisine yabancılaşır ve başka bir gerçekliğe dönüşür. Bu Baudrillard'ın göre gerçekliğin yitimiyle üst gerçekliğe (hipergerçeklik) dönüşen simülasyondan başka bir şey değildir”.

$\mathrm{Bu}$ çalışma kamuflajı çağdaş sanat sürecinde bir strateji olarak ele alan sanatçıların çalışmalarına ilişkin yapılan analizde, çağdaş sanatçıların kamuflajı çağın yeni bir gerçekliği olarak ele aldıkları görülmektedir. Yeni gerçekliklerin üretildiği çağda sanatçılar da bu amaç doğrultusunda insanları, artık yitirilmiş olan gerçeğe inandırmayı hedeflemektedir. Sanatçıların daha çok performans, beden sanatı, fotoğraf, video yerleştirme gibi farklı uygulama disiplinleri aracılığı ile ortaya koydukları bu simülasyonlar oyun, bedenleme, kimlik, cinsiyet, saklanma gibi kavramlar üzerinden İzleyenlere/katılımcılara gerçeğin hala var olduğunu göstererek hipergerçekliğin varlığını gizlemek ve bu yolla onları denetim altında tutmak amacına yöneliktir. 
Sonuç olarak kamuflaj ister iletişim ister kimlik, isterse yabancılaşma ve cinsiyet olsun, bireyin somut ya da soyut, tüm yönlerinin stratejik olarak gizlenmesi ile yeniden sorgulanarak açığa çıkarılması çabasıdır.

\section{KAYNAKÇA}

Bauman, Z. (2000), Postmodernlik ve Hoşnutsuzlukları, (Çev: İsmail Türkmen), Ayrıntı Yayınları, İstanbul.

Behrens, R. R. (1977), Camouflage, Cubism, and Creativity: The Dissolution of Boundaries, J. Creative Behavior 11, 91.

Behrens R., R., (1978). On Visual Art And Camouflage Leonardo, Vol. 11, pp. 203-204. Pergamon Press Ltd. 19.İngiltere.

Behrens, R. R. (1981), Art and Camouflage: Concealment and Deception in Nature, Art and War (Cedar Falls, IA: North American Review / University of Northern Iowa.

Behrens, R. R. (1996). Camouflage, in Jane Turner, ed., The Dictionary of Art, London and New York: Grove Dictionaries.

Behrens, R. R. (1998), "On Max Wertheimer and Pablo Picasso: Gestalt Theory, Cubism and Camouflage" in Gestalt Theory 20, No. 2.

Behrens, R. R. (1999), "The Role of Artists in Ship Camouflage During World War I" in Leonardo 32, No. 1 pp. 53-59.

Behrens R. R. (2002), Art. Design and Modem Camouflage, Iowa.

Behrens, R. R. (2005), Architecture, Art and Camouflage" in Lotus International Issue 126, 74-83.

Blechman, H. (2004), An Encyclopaedia of Camouflage: Nature, Military and Culture, 2 voll. London.

Brielmaier, I. (2006), Lalla Essaydi. In Rodrigo, Alonso, Vitamin Ph: New pespectives in photography. London, Phaidon Press,

Bouchet, R. (2016), Mémoires du camoulage de la Grande Guerre dans l'art contemporain, Annales de Bretagne et des Pays de l'Ouest Anjou. Maine. Poitou-Charente. Touraine 123-3 / 2016 La Grande Guerre, inspiration des artistes de 1914 à nos jours.

Baiges, M. M. (2007), Camuflaje. Engaño y ocultación en el arte contemporáneo, Madrid,

Baiges M. M, ve Pizarro, P. (2009), Camuflajes, Exhibition Catalogue, Madrid,

Baiges, M. M., (2016), Il Camouflage Mimetico E Il Problema Della Rappresentazione Pittorica, Arti e Culture Visive, Dipartimento delle Arti, Alma Mater Studiorum - Università di Bologna.

Chesney, C.H.R. (1941), The Art of Camouflage, R. Hale, London

Cork, R. (1994), A Bitter Truth: Avant-Garde Art and The Great War. New Haven, Connecticutand London.

Coutin, C. (2014), Camouflage, İnternational Encyclopedia Of The First World War, 08 October 2014

Dalí, S. (1942), Total Camouflage for Total War, Esquire, 18 (2), 64-67.

Darwin, C. (1976), Türlerin Kökeni, (çev. Öner Ünalan, 2. baskı, Onur Yayınları, Ankara, Nisan 1976).

Elias, A, (2011) Camouflage Australia: Art, Nature, Science and War, Sydney University Pres, Australia

Elias, A. (2012). Camouflage and Surrealism. War, Literature and the Arts (WLA), 24, 1-25

Erişti S. D. B. (2017). Görsel Araştırma Yöntemleri, Teori, Uygulama Ve Örnek, Pegem Akademi Yayınları, Ankara. 
Fabbri, P. (2015), Sémiotique, Stratégies, Camouflage, Actes Sémiotiques no,118.

Gültekin T. ve Buse P, (2016), Sanatta Toplumsal Eleştiri Sürecinde Ironi Kavramı, Dil ve Söylem Analizi, DOI: 10.7816/idil-05-19-09 idil, 2016, Cilt 5, Say1 19, Volume 5, Issue 19

Güzel M. (2015). Gerçeklik Illkesinin Yitimi: Baudrillard'ın Simülasyon Teorisinin Temel Kavramları, FLSF (Felsefe ve Sosyal Bilimler Dergisi), 2015 Bahar, say1: 19, s. 65-84.

Hébert, H. (2019), Camouflage Art Contemporain Africain, Espace Sculpture, Document généré le 4 juil. 2019 08:11

Honef, K. (1992), Contemporary Art, Benedict, Taschen.

Kuspit, D. (2010), Sanatın Sonu, Çev. Yasemin Tezgiden, Metis Yayınları, İstanbul.

Özdal, I, (2013), Oryantalizm, Görsel İzler ve Günümüz Fotoğraf Sanat, Yedi; Sanat Tasarım ve bilim Dergisi, Say1 9, 61-73. Dokuz Eylül Üniversitesi, İzmir.

Pettersson R. (2018). Visual camouflage, Journal of Visual Literacy, DOI: 10.1080/1051144X.2018.1529884

Read, H. (1974), A Concise History Of Modern Painting, Thames And Hudson Press. London

Richardson, B. (1999), Andy Warhol: Camouflage, New York Gagosian Gallery.

Şahiner, R. (2015), Çağgdaş Sanatta Temsiliyet Krizi, Ütopya Yayınevi, Ankara.

Tachev, M. (2015), Influence Of Art On The Camouflage Design, Journal Of Industrial Design And Engineering Graphics, Volume 10, Special Issue, 68, Icegd, June 2015

Tsoutas N. (2013), Camouflage Seems To Be The Only Game In Town, Camouflage Cultures, Surveillance, Communities, Aesthetics \& Animals, The University of Sydney, 2013

White, E. (2017), Modernist Cultures, Technicities of Deception: Dazzle Camouflage, Avant-Gardes and Sensory Augmentation in the First World War, Edinburgh University Press 12.1: 36-58

Watson, R. (2009), Mapping and Contemporary Art, The Cartographic Journal Vol. 46 No. 4 pp. 293 307 Art \& Cartography Special Issue, November 2009

Zhao, X. ve Belk R., (2008), Politicizing Consumer Culture: Advertising's Appropriation of Political Ideology in China's Social Transition, in: Journal of Consumer Research, 231-244.

Zohar, A. (2014), Strategies of Camouflage: Depersonalization, Schizoanalysis and Contemporary Photography, London; Bloomsbury Academic.

\section{İnternet Kaynakları}

Bolin L., Vigilance, survival instinct and simulation, http://www.galerieparisbeijing.com/artist/liubolin/\# erişim tarihi: 20.11 .2018

Esmer H. (2015) http://hayriesmer.com/makale/cagdas-sanatta-temsiliyet-iliskilerini-nasilokumali/90?n=tr. Erișim 21.07.2019

Errazzouki, S. (2012), Artistic Depictions of Arab Women: An Interview with Artist Lalla Essaydi, https://www.jadaliyya.com/Details/25958, Erişim: 28.07.2019.

Pratt, K. (2007), Out of Meat District, http://www.desireepalmen.nl/2007.php. Erişim: 25.07.2019

https://media.turuz.com/Dictionary/2018/0968-Yabanci_Sozcuklere_Turkce_Qarshiliqlar-Turklib83s.pdf

Silvia, M. (2012), Camouflage Revealed. Liu Bolin and the Art of Mimetic Performance,2012. http://www.galerieparisbeijing.com/artists/liubolin/articles.html erişim tarihi: 20.11.2018

Cecilia P, https://www.lensculture.com/articles/cecilia-paredes-eternally-camouflaged 15.11.2018 
Warhol A. (2018) https://www.warhol.org/lessons/camouflage-sound-activity/). Erişim: 18.11.2018. Warhol (2018b)https://revolverwarholgallery.com/portfolio/camouflage-full-suite/ Erişim: 18.11.18

\section{Görsel Kaynaklar}

Görsel 1. Henri Matisse, Luxe, Calme Et Volupté, 1904, Tuval Üzerine Yağlıboya, 94X116, Orsay Müzesi, Paris. https://www.hippostcard.com/listing/matisse-henri-luxe-calme-etvolupte/16350182, Erişim 27.09.2019.

Görsel 2. Roy Lichtenstein, Little Aloha, 1962, Tuval Üzerine Akrilik ve İpek Bask1, 16.5 x 16.5 cm. https://www.christies.com/lotfinder/Lot/richard-pettibone-b-1938-roy-lichtenstein-5680280details.aspx, Erişim 27.09.2019.

Görsel 3. Warhol, Camouflage Self-Portrait, 1986, Acrylic Silkscreen İnk On Canvas, 101.6 by $101.6 \mathrm{~cm}$. $\quad$ https://www.mutualart.com/Artwork/CAMOUFLAGE-SELF PORTRAIT/D529B21FDAED5C13_Erişim tarihi: 28.10.2018

Görsel 4. Alighiero Boetti, Tutto, 1988-1989, Nakış, 231 x 212 cm. http://www.artnet.com/artists/alighiero-boetti/tutto-7hrf5d8cFSz4uZaUgvOzIw2 Erişim: 28.07.2019.

Görsel 5. Emma Hack, Evolution Crocodile 2008, C-Print, 120 x 90 cm. http://www.emmahackartist.com.au/emma_art/emma_evolution.html\#.W_Wya-gzaM8:Erişim tarihi:04.11.2018

Görsel 6. Essaydi, Les Femmes du Maroc, Harem Beuty, 2008, Aliminyum Bask1, 122 X76 cm https://www.jacksonfineart.com/artists/lalla-essaydi/works/27616/_Erişim tarihi: 14.11.2018

Görsel 7. Desiree Palmen, Police Camera Christian Quarter, Polis kameras1, 2006, 92x70 cm. http://www.desireepalmen.com/large.php?foto=jerusalempolitie.jpg\&titel=Police\%20(Latin\% 20Patriachate). Erişim 20.07.2019

Görsel 8. Lee Yong Baek, Angel-Soldier Version 23 dk video, 2011, https://www.flashartonline.com/article/hallyu/_Erişim tarihi: 20.11.2018

Görsel 9. Liu Bolin, Hiding in the City No. 93 - Supermarket No. 2, photograph, 118x150 cm https://perezartsplastiques.com/2016/02/28/le-geste-dans-lart/_Erişim tarihi: 03.11.2018

Görsel 10. Ana Mendieta, Untitled, 1981, Photography lifetime black and white photograph $20.3 \times 25.4$ $\mathrm{cm}$. https://www.artbasel.com/catalog/artwork/75360/Ana-Mendieta-Untitled Erişim: 27.07.2019.

Görsel 11. Cecilia Paredes, Corinthians, 2014, Digital photograph 120 x 120 cm. https://beatrizgilgaleria.com/obras-en-catalogo/cecilia-paredes-fotografia/corinthians-bluedetail_Erişim tarihi: 18.11.2018.

Görsel 12. Kim Joon, Blue fish, 2008, photographs, c-print, $101.6 \mathrm{x} 101,6 \mathrm{~cm}$. https://littlearrow.files.wordpress.com/2011/05/kim-joon-cradle-song-blue-fish-2009.jpg Erișim:21.11.2018.

Görsel 13. Parastou Forouhar, Red Is My Name, Green Is My Name III, 201, Digital drawing on Photo Rag, $80 \times 80 \mathrm{~cm}$. https://www.artsy.net/artwork/parastou-forouhar-red-is-my-name-green-ismy-name-iii

Görsel 14. Kusama, The Obliteration Room, 2002, collaboration between Kusama and Queensland Art Gallery Erişim tarihi: 14.11.2018 http://www.artfixdaily.com/artwire/release/6315-five-citytour-across-us-and-canada-for-\%E2\% $80 \% 9$ Cyayoi-kusama-infinity-mi___Erişim tarihi: 07.11 .2018 